\title{
Silencing Dicer-Like Genes Reduces Virulence and sRNA Generation in Penicillium italicum, the Cause of Citrus Blue Mold
}

\author{
Chunxiao Yin ${ }^{1}$, Hong Zhu ${ }^{2}{ }^{\mathbb{D}}$, Yueming Jiang ${ }^{2,3}{ }^{\mathbb{D}}$, Yang Shan ${ }^{1, *}$ and Liang Gong ${ }^{2,3, *}$ \\ 1 Long Ping Branch, Graduate School of Hunan University, Changsha 410125, China; chunxiaoyin@scbg.ac.cn \\ 2 Key Laboratory of Plant Resource Conservation and Sustainable Utilization, Key Laboratory of Post-Harvest \\ Handling of Fruits, Ministry of Agriculture, Guangdong Provincial Key Laboratory of Applied Botany, \\ South China Botanical Garden, Chinese Academy of Sciences, Guangzhou 510650, China; \\ zhuhong@scbg.ac.cn (H.Z.); ymjiang@scbg.ac.cn (Y.J.) \\ 3 Core Botanical Gardens, Chinese Academy of Sciences, Guangzhou 510650, China \\ * Correspondence: sy6302@sohu.com (Y.S.); Lianggong@scbg.ac.cn (L.G.)
}

Received: 2 January 2020; Accepted: 31 January 2020; Published: 4 February 2020

\begin{abstract}
The Dicer protein is one of the most important components of RNAi machinery because it regulates the production of small RNAs (sRNAs) in eukaryotes. Here, Dicer1-like gene (Pit-DCL1) and Dicer2-like gene (Pit-DCL2) RNAi transformants were generated via pSilent-1 in Penicillium italicum (Pit), which is the causal agent of citrus blue mold. Neither transformant showed a change in mycelial growth or sporulation ability, but the pathogenicity of the Pit-DCL2 RNAi transformant to citrus fruits was severely impaired, compared to that of the Pit-DCL1 RNAi transformant and the wild type. We further developed a citrus wound-mediated RNAi approach with a double-stranded fragment of Pit-DCL2 generated in vitro, which achieved an efficiency in reducing Pi-Dcl2 expression and virulence that was similar to that of protoplast-mediated RNAi in P. italicum, suggesting that this approach is promising in the exogenous application of dsRNA to control pathogens on the surface of citrus fruits. In addition, sRNA sequencing revealed a total of 69.88 million potential sRNAs and 12 novel microRNA-like small RNAs (milRNAs), four of which have been predicated on target innate immunity or biotic stress-related genes in Valencia orange. These data suggest that both the Pit-DCL1 and Pit-DCL2 RNAi transformants severely disrupted the biogenesis of the potential milRNAs, which was further confirmed for some milRNAs by qRT-PCR or Northern blot analysis. These data suggest the sRNAs in P. italicum that may be involved in a molecular virulence mechanism termed cross-kingdom RNAi (ck-RNAi) by trafficking sRNA from P. italicum to citrus fruits.
\end{abstract}

Keywords: citrus; Penicillium italicum; pathogenicity; RNA interference; cross-kingdom RNAi; Dicer; small RNA

\section{Introduction}

Citrus fruit production exceeded 140 million tons in 2016, accounting for one-fifth of the total fruit production worldwide [1]. After harvest, citrus fruits are commercially handled in packing houses in order to maintain their postharvest quality, to increase their shelf life, as well as to reduce losses due to pathogen infection. Citrus blue mold, caused by Penicillium italicum, is one of the most destructive pathogens of postharvest citrus fruits, resulting in losses of up to $80 \%$ [2].

Advancing our knowledge regarding the molecular mechanisms underlying interactions between citrus fruit and P. italicum is profitable to reduce postharvest losses. Regulating the ambient $\mathrm{pH}$ of the host is considered to be one of the pathogenic mechanisms of Penicillium species. These pathogens can produce organic acids and deplete ammonium to acidify the ambient environment of citrus fruits 
during decay development, which is a cue for virulence enhancement [3]. In addition, suppressing host defenses has been considered another available pathogenic mechanism of P. digitatum. Macarisin et al. demonstrated that $P$. digitatum can suppress the host's production of reactive oxygen species, while the non-host pathogen P. expansum can trigger a 63-fold increase in hydrogen peroxide production in citrus fruits [4]. In addition, comparative genomics has been developed to analyze the molecular basis of fungal pathogenicity, and a large number of putative virulence factors, including Carbohydrate-Active enZymes, proteases, and oxidoreductases, were identified in Penicillium species, these genes were up-regulaed during the infection process, which is highly related to their pathogenicity $[5,6]$. Recently, cross-kingdom RNA (Ribonucleic Acid) interference (ck-RNAi) mediated by small RNAs (sRNAs) has been recognized as an innovative molecular mechanism to modulate fungal virulence [7]. However, the presence and function of sRNAs in P. italicum has never been elucidated.

Dicer, an RNase III-like endonuclease that is a major component of RNAi machinery, processes long-chain double-stranded RNA (dsRNA) into 21-25 nt-long small interfering RNAs (siRNAs) [8]. These siRNAs are integrated with the Argonaute (AGO) family proteins to form the RNA-induced silencing complex (RISC), guiding the degradation or translational inhibition of the target mRNA [9]. It is well-known that the RNAi pathway in filamentous fungi is associated with the dicer-dependent process in the generation of siRNAs, including microRNAs (miRNAs) and small interfering RNAs (siRNAs) [10]. In addition, Dicer-like genes play important roles in fungal conidiation and pathogenicity; for example, Meng et al. (2017) reported that a Dicer-like gene 2 mutant of the entomopathogenic fungus Metarhizium robertsii exhibited a 55.8\% reduction in conidial yield [11]. In the plant pathogenic fungus Fusarium graminearum, ascospore discharge was decreased in the Dicer-like gene 1 deletion mutant and was completely blocked in the Dicer-like gene 1 and 2 double deletion mutant [12]. Dicer-like proteins regulate growth and conidiation in Colletotrichum gloeosporioides, and the double mutation abrogated the ability to penetrate Hevea brasiliensis [13]. These findings suggest that filamentous fungi employ RNAi-related pathways in various physiological processes to adapt to different environmental conditions; however, the RNAi machinery has never been reported in P. italicum, although it is the most serious pathogen causing the decay of citrus fruits at the postharvest stage.

sRNAs were first discovered in the model fungus Neurospora crassa in 2010 [14]. Since then, they have been widely reported in other filamentous fungi, such as Trichophyton rubrum [15], Sclerotinia sclerotiorum [16], Fusarium oxysporum [17], Blumeria graminis [18], and Valsa mali [19]. However, fungal sRNAs remain functionally uncharacterized, although they play crucial roles in animals and plants during diverse developmental processes under both normal and stress conditions [20]. However, the rapid development of sRNA sequencing technology provides a novel strategy to detect and identify precursors or mature sequences of sRNA in fungi [21] and thus can be a useful tool to identify sRNAs in filamentous fungi.

The aim of this study was to investigate the function of Dicer-like genes in relation to the pathogenicity of P. italicum by using protoplast and citrus wound-mediated RNAi technology, in addition to discovering and characterizing the sRNAs in the RNAi transformants by using the Illumina sequencing platform. Our study revealed the potential linkage between the RNAi machinery and the pathogenicity of $P$. italicum, and highlighted the probability of utilizing RNAi as a tool to control P. italicum infection in postharvest citrus fruits.

\section{Materials and Methods}

\subsection{Fungal Strain and Plasmid}

P. italicum was isolated from a decayed citrus fruit, as reported in a previous study [22]. This strain was maintained on potato dextrose agar (PDA) containing $0.4 \%$ potato extract, $2 \%$ dextrose, and $2 \%$ agar at $25 \pm 2{ }^{\circ} \mathrm{C}$ for 5 days. The spores from a 5 day-old culture were collected, filtered, and adjusted to a suitable concentration using a hematocytometer and were used in the following experiments. The pSilent-1 plasmid containing the hygromycin resistance gene as a fungal selection marker, and the 
promoter and terminator of the trpC gene from Aspergillus nidulans [23] was kindly provided by Pro. QB Hu (College of Agriculture, South China Agricultural University, Guangzhou, China).

\subsection{Construction of Silencing Vectors}

Two Dicer-like genes were annotated from our sequenced P. italicum genome (GCA_002116305.1) and released in GenBank under accession numbers MN537145 and MN537146. The partial CDS sequences of Dicer 1-like gene DCL1 (582 bp) and Dicer 2-like gene DCL2 (406 bp) were separately amplified using gene-specific primers (Table S1). The silencing vector was constructed using pSilent-1 by inserting the sense sequence of the partial CDS at the Xhol/HindIII sites and the reverse complement sequence of the partial CDS at the KpnI/ApaI sites, according to Chen et al. [23]. The prepared silencing vectors were further confirmed by DNA sequencing at IGE Biotechnology (Guangzhou, China). The empty pSilent-1 plasmid was used as a negative control.

\subsection{Preparation of Protoplasts, Transformation and Screening}

Protoplasts were prepared, as described by Visser et al. [24], with minor modifications. Briefly, conidial suspensions $\left(10^{7}\right.$ spores $\left./ \mathrm{mL}\right)$ were cultured in potato-dextrose broth (PDB) containing $0.4 \%$ potato extract and $2 \%$ dextrose with shaking at $200 \mathrm{rpm}$ for $48 \mathrm{~h}$ at $28^{\circ} \mathrm{C}$. Then, the mycelia were collected and washed with a $0.8 \mathrm{M} \mathrm{NaCl}$ solution. A liquid enzyme mixture consisting of driselase (Solarbio, Beijing, China), cellulase (Solarbio, Beijing, China), and sterile D-glucose solution (Sigma-Aldrich, Guangzhou, China) was used to fully digest fungal cell walls. The obtained protoplasts were further examined with an optical microscope to ensure complete digestion of the cell walls.

Transformation was performed, as described by Proctor et al. [25], with the following modifications. The constructed pSilent- 1 plasmid $(10 \mu \mathrm{g}, 800 \mathrm{ng} / \mu \mathrm{L})$ was mixed with $100 \mu \mathrm{L}$ of the protoplasts solution prepared, as described above $\left(10^{8}\right.$ cells $\left./ \mathrm{mL}\right)$, and incubated at room temperature for $10 \mathrm{~min} ; 200,400$, and $800 \mu \mathrm{L}$ of $50 \%$ PEG 4000 solution ( $50 \mathrm{mM}$ Tris- $\mathrm{HCl}(\mathrm{pH} 8.0)$ and $50 \mathrm{mM} \mathrm{CaCl}_{2}$ ) was then gradually added and mixed thoroughly with the protoplast solution. After $30 \mathrm{~min}$ at room temperature, the supernatant was removed by centrifugation $\left(4^{\circ} \mathrm{C}, 3000 \times g, 5 \mathrm{~min}\right)$, and the protoplasts were resuspended in $1 \mathrm{~mL}$ of STC solution ( $50 \mathrm{mM} \mathrm{CaCl}_{2}, 50 \mathrm{mM}$ Tris $\mathrm{HCl}$ ( $\mathrm{pH}$ 8.0), $0.8 \mathrm{M}$ sorbitol). PDA ( $5 \mathrm{~mL}$, with the addition of $0.6 \mathrm{M}$ glucose) was added and gently mixed with the protoplast solution. The mixtures were poured evenly on PDA plates ( $0.6 \mathrm{M}$ glucose, $200 \mu \mathrm{g} / \mathrm{mL}$ hygromycin B) and incubated at $28^{\circ} \mathrm{C}$ for $48 \mathrm{~h}$ until transformant mycelia were visible. The transformants were subcultured alternately on PDA plates containing hygromycin B $(300 \mu \mathrm{g} / \mathrm{mL})$ or not containing hygromycin B three times.

The wild-type strain and the transformants were cultured separately in PDB medium with shaking (200 rpm) for three days. Genomic DNA was extracted by using a HiPure Fungal DNA Mini Kit (Magen, Shanghai, China). Screening was performed by amplifying the hygromycin resistance gene (hph) with specific primers (Table S1). The amplification reaction contained $200 \mathrm{ng}$ of DNA, $0.5 \mu \mathrm{M}$ hph forward and reverse primers, $25 \mu \mathrm{L}$ of $2 \times$ reaction polymerase buffer mix (TSINGKE, Beijing, China), and sterile water was added to a total volume of $50 \mu \mathrm{L}$. Then, the following PCR (Polymerase Chain Reaction) conditions were used: $94{ }^{\circ} \mathrm{C}$ for $4 \mathrm{~min}$ as the initial denaturation step; followed by 35 cycles at $94{ }^{\circ} \mathrm{C}$ for $30 \mathrm{~s}$ for denaturation, $60^{\circ} \mathrm{C}$ for $30 \mathrm{~s}$ for primer annealing, and $72{ }^{\circ} \mathrm{C}$ for $1 \mathrm{~min}$ for DNA strand synthesis; and a final extension step at $72{ }^{\circ} \mathrm{C}$ for $10 \mathrm{~min}$. Amplified products were stained with EtBR (Sigma, Saint Louis, MO, USA) in 1.0\% agarose gel electrophoresis and visualized by GelDoc-It 310 Imaging System. (Thermo Fisher Scientific, Boston, MA, USA).

\subsection{Biomass Assay and Pathogenicity Testing}

To compare the biomass of the mycelia and spores of the prepared strains, $100 \mu \mathrm{L}$ of a conidial suspension $\left(10^{7}\right.$ spores $\left./ \mathrm{mL}\right)$ of the transformants and the wild-type strain were inoculated into $50 \mathrm{~mL}$ of PD liquid medium in a $100 \mathrm{~mL}$ conical flask and placed on a shaker at $200 \mathrm{rpm}$ for 3 days at $28^{\circ} \mathrm{C}$. The mycelium was collected by vacuum extraction with a Buchner funnel and filter paper; after freeze drying under a vacuum for $12 \mathrm{~h}$, the mycelium was weighed. Conidiospores were harvested by 
filtering $(0.4 \mu \mathrm{m})$ and were further counted under an optical microscope with a hemocytometer. Each treatment was repeated three times, and four parallel experiments were performed for each treatment.

Inoculation of the P. italicum strains on sugar oranges, which is a Chinese mandarin with a special feature of granulated epidermis pattern and is a local citrus fruit of Guang dong province, was performed according to our reports [22]. Briefly, the matured citrus fruits with the diameter of around $6 \mathrm{~cm}$ were chosen and cleaned with sterile water, and then dabbed with $70 \%$ ethanol within $10 \mathrm{~s}$. After air drying, small wounds ( $5 \mathrm{~mm}$ deep and $2 \mathrm{~mm}$ wide) were created by a sterile knife tip at two positions opposite one another near the equator of the fruits. Conidial suspensions $(10 \mu \mathrm{L}$, $10^{6}$ spores $/ \mathrm{mL}$ ) from the transformants and the wild-type strain were inoculated separately on the surface of the wounds, and the citrus fruits were then kept in a chamber at $28{ }^{\circ} \mathrm{C}$ for 5 days. Thirty citrus fruits were used for each treatment with two independent biological repeats. On days 3,4 , and 5 after inoculation, the diameters of the infected sites were measured, and the samples of the infected epidermis were collected and stored at $-80^{\circ} \mathrm{C}$ for gene expression analysis.

\subsection{Preparation of Pit-DCL2 dsRNA and Application on the Citrus Fruit Surface}

The double-stranded RNA (dsRNA) of Pit-DCL2 was synthesized by using a HiScribe kit (NEB, Beijing, China) following the manufacturer's protocols. The specific primers Pit-DCL2-F and Pit-DCL2-R, both of which contained a T7 promoter sequence at the $5^{\prime}$ end (Table S1), were designed for dsRNA amplification. dsGFP was used as the negative control, and the concentration of the prepared dsRNA was confirmed with a Nanodrop 2000 (Thermo Fisher Scientific, Boston, MA, USA). Two different methods were used to apply dsRNA to the surface of the citrus fruits: In the first method, two wounds opposite of each other on the equator of the sugar orange were created with a sterile knife, and 200 and $800 \mathrm{ng}$ of dsDCL2 or $800 \mathrm{ng}$ dsGFP was dropped onto the wound surfaces. After $2 \mathrm{~h}$, $10 \mu \mathrm{L}\left(10^{5}\right.$ spores $\left./ \mathrm{mL}\right)$ of conidial suspension was inoculated at the same positions on the wounds. In the second method, 200 and $800 \mathrm{ng}$ of dsDCL2 or $800 \mathrm{ng}$ of dsGFP were separately incubated with protoplasts $\left(10^{7}\right.$ cells/mL) in PTC solution at room temperature for $1 \mathrm{~h}$, and the mixture $(10 \mu \mathrm{L})$ was then inoculated on each wound. Four experimental groups were arranged, including the control group (without dsRNA), dsGFP (800 ng), dsDCL2 (200 ng), and dsDCL2 (800 ng). Ten sugar oranges were used for one parallel experiment and a total of thirty sugar oranges were tested for each experimental group, and the treated fruits were placed in an incubator at a constant temperature of $28{ }^{\circ} \mathrm{C}$ for 5 days. The decay index was calculated according to the formula: $\Sigma$ (decay scale $\times$ proportion of fruits corresponding to each scale) $/ 5 \mathrm{n} \times 100 \%(n=60)$ [22], and the infected citrus epidermises were collected and stored at $-80^{\circ} \mathrm{C}$ for gene expression analysis.

\subsection{Small RNA Sequencing}

Nine sRNA libraries (three DCL1RNAi, three DCL2RNAi and three wild-type) containing the total RNA with lengths of 18-30 nt were prepared by using TruSeq small RNA library kits (Illumina Trading, Shanghai, China). The libraries were barcoded and sequenced using the Illumina HiSeq ${ }^{\mathrm{TM}}$ 2500 SE50 platform by Magigene Biotechnology Co. (Guangzhou, China). Raw sRNA-seq reads were first processed through custom Perl and python scripts to remove reads containing poly-N and adapter sequences and low-quality reads. In addition, the Q20, Q30, and GC content of the raw data were calculated. Then, reads with a length of 18-30 nt were selected from the clean reads for all downstream analyses. The total clean sRNAs were mapped to the P. italicum PHI-1 genome sequence (GenBank assembly accession number: GCA_000769765.1) by Bowtie (http://bowtie-bio.sourceforge.net/index. shtml) with a mismatch value of 0 , and the expression and nucleotide length distribution, and the $5^{\prime}$ terminal nucleotide composition were analyzed with a set of Perl and R scripts. The mapped sRNAs were then aligned with the Rfam database (version 14.0) to remove sRNAs originating from rRNAs, tRNAs, snRNAs, and snoRNAs (http://rfam.xfam.org/). miRBase 20.0 (http://www.mirbase.org/) was used as a reference to find known miRNA. Reads overlapped with protein-coding genes and repeat sequences were analyzed with BEDTools (https://bedtools.readthedocs.io/en/latest/). Candidate miRNAs were 
predicted with miREvo [26] and mirdeep2 [27] using the default settings. The secondary structures of the miRNAs were predicted using RNAfold [28]. The sRNA targets were predicted by TargetFinder 1.6 [29] with the cDNA sequences of an orange species Citrus sinensis (www.citrusgenomedb.org/). All raw data generated in this study were deposited in the NCBI Sequence Read Archive database under the accession no. GSE138683.

\section{7. qRT-PCR and Northern Blot Analysis}

Quantitative real time PCR (qRT-PCR) analysis was performed using a 7500 Fast Real-Time PCR System (Applied Biosystems, Boston, MA, USA) with the following conditions: The in front of total RNA was extracted using the HiPure Mini Kit (Magen, Shanghai, China) according to the manufacturer's specifications. cDNA was generated with PrimeScript ${ }^{\mathrm{TM}}$ RT Master Mix (TaKaRa, Tokyo, Japan) following the manufacturer's instructions. qRT-PCR was conducted using $20 \mathrm{ng}$ of cDNA, $10 \mu \mathrm{L}$ of $2 \times$ TB Green Premix Ex Taq ${ }^{\mathrm{TM}} \mathrm{II}$ (TaKaRa), $0.4 \mu \mathrm{L}$ of forward primers and reverse primers (Table S1), $0.4 \mu \mathrm{L}$ of ROX Reference Dye II (TaKaRa), and the reaction volume was brought to a total volume of $20 \mu \mathrm{L}$ with sterile water. The relative expression levels of target genes were first normalized to the endogenous reference gene by using the formula $2^{-\Delta \Delta \mathrm{T}}$ [30], then normalized relative to the level of gene transcripts in the control group, and the $\beta$-actin gene was used as the reference gene (Table S1). All experiments were repeated three times.

For Northern blot analysis, $100 \mu \mathrm{g}$ of total RNA was resolved on a $15 \%$ urea denaturing polyacrylamide gel and transferred to Amersham Hybond ${ }^{\mathrm{TM}}-\mathrm{NX}$ membranes (GE Healthcare, USA). The 21-22-nt microRNA oligonucleotide probes (Table S1) were labeled using a Biotin 3' End DNA Labeling Kit (Thermo Fisher Scientific). The U6 probe was used as the control to confirm uniform loading. Membranes were hybridized for $16 \mathrm{~h}$ at $37^{\circ} \mathrm{C}$ and washed three times at the same temperature with stringent washing buffer containing $1 \%$ SDS and $1 \times$ SSC. The membranes were blocked, washed, and chromogenically reacted with a Chemiluminescent Nucleic Acid Detection Module (Thermo Fisher Scientific); hybridization signals were then detected using a ChemiDoc ${ }^{\mathrm{TM}}$ Touch Imaging System (Bio-Rad, Hercules, CA, USA).

\section{Results}

\subsection{Generation of Silencing Transformants of Dicer-Like Genes in P. italicum}

The silencing vectors expressing hairpin dsRNA of the DCL1- and DCL2-like gene fragments were constructed and transformed separately into P. italicum. As shown in Figure 1, the transformants were identified by the expected amplicon of $519 \mathrm{bp}$ and the absence of this amplicon in the wild-type strain (Figure 1a). Spore production was not significantly different between the wild-type strain and the transformants, but the DCL1RNAi and DCL2RNAi transformants had slightly higher mycelial production than the blank vector control and the wild-type strain (Figure 1b,c). However, the spore and hyphal morphology exhibited no visible changes in the transformants (data not shown). In addition, the expression levels of the DCL1-like gene and DCL2-like gene in the transformants were significantly reduced by 5.8 and 2.4 fold, respectively, compared to those in the wild-type strain and by 5.8 and 3.0 fold, respectively, compared to those in the blank vector-transformed strain (Figure 1d), suggesting that we obtained RNAi transformants with downregulated DCL-like genes in P. italicum. 


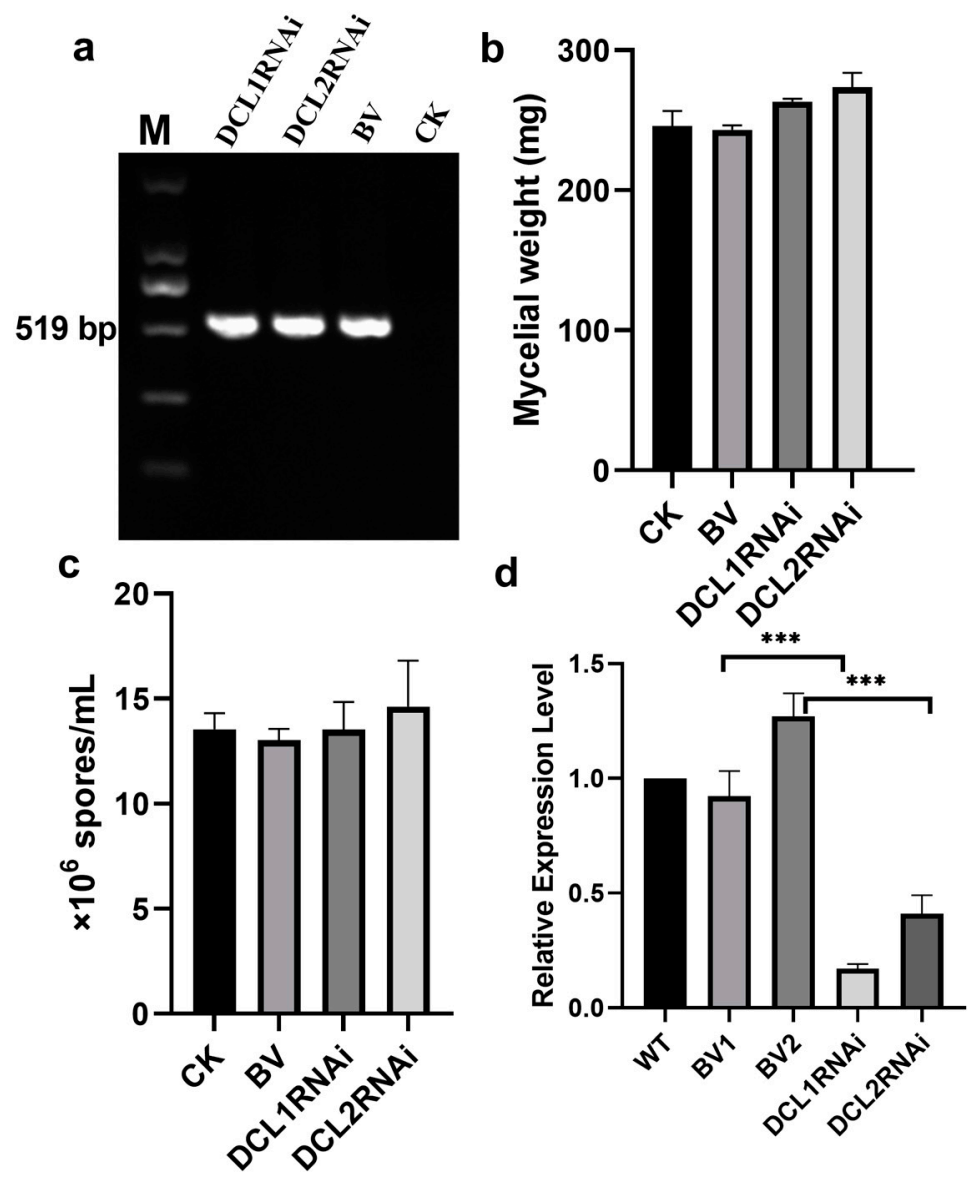

Figure 1. Features of the RNAi transformants. (a) PCR screening based on the amplification of the hygromycin resistance gene; (b) mycelial dry weight from wild-type P. italicum and the RNAi transformants; (c) spore number from wild-type P. italicum and the RNAi transformants; (d) qPCR expression analysis of the Dicer-like genes in the RNAi transformants and wild-type strain after culture in PDB (potato dextrose agar) for 5 days. CK (wild-type), BV (blank vector transformant), DCL1RNAi (Dicer-like1 gene transformant) and DCL2RNAi (Dicer-like 2 gene transformant), and BV1 and BV2 mean the relative expression level of Dicer-like 1 and Dicer-like 2 in the blank vector transformant, respectively. Each bar represents a mean \pm standard error $(n=3$ or 4$)$, and the asterisk indicates a significant difference $\left.{ }^{* * *}, p<0.001\right)$.

\subsection{The Effect of Dicer-Like Gene Silencing on the Infection of Citrus Fruits by P. italicum}

The pathogenicity of the DCL1RNAi and DCL2RNAi transformants was tested on sugar oranges. As shown in Figure 2, the pathogenicity of the DCL1RNAi transformant was not significantly different compared to that of the wild-type or blank plasmid-transformed strain, but the ability of the DCL2RNAi transformant to infect the citrus epidermis was significantly limited; however, the expression profile of the DCL-like genes in infected citrus tissues revealed that both Pit-Dcl1 and Pit-Dcl2 were significantly decreased after inoculation on day 4 and day 5 (Figure 3). These results suggested that Pit-DCL2 but not Pit-DCL1 participates in the pathogenicity of $P$. italicum. Furthermore, we performed the pathogenicity test again by using the protoplast and citrus peel-mediated RNAi methods, respectively, in which the prepared dsDCL2 construct was treated to the protoplast of P. italicum or citrus peel before the infection; as shown in Figure 4, although the method of protoplast-mediated RNAi seemed more effective in achieving an RNAi response, both methods produced the expected results of downregulating the Pit-DCL2 gene and weakening the pathogenicity of P. italicum. However, this efficiency was dose-dependent, suggesting that higher concentrations of the treated dsRNA could achieve higher gene silencing efficiency. 


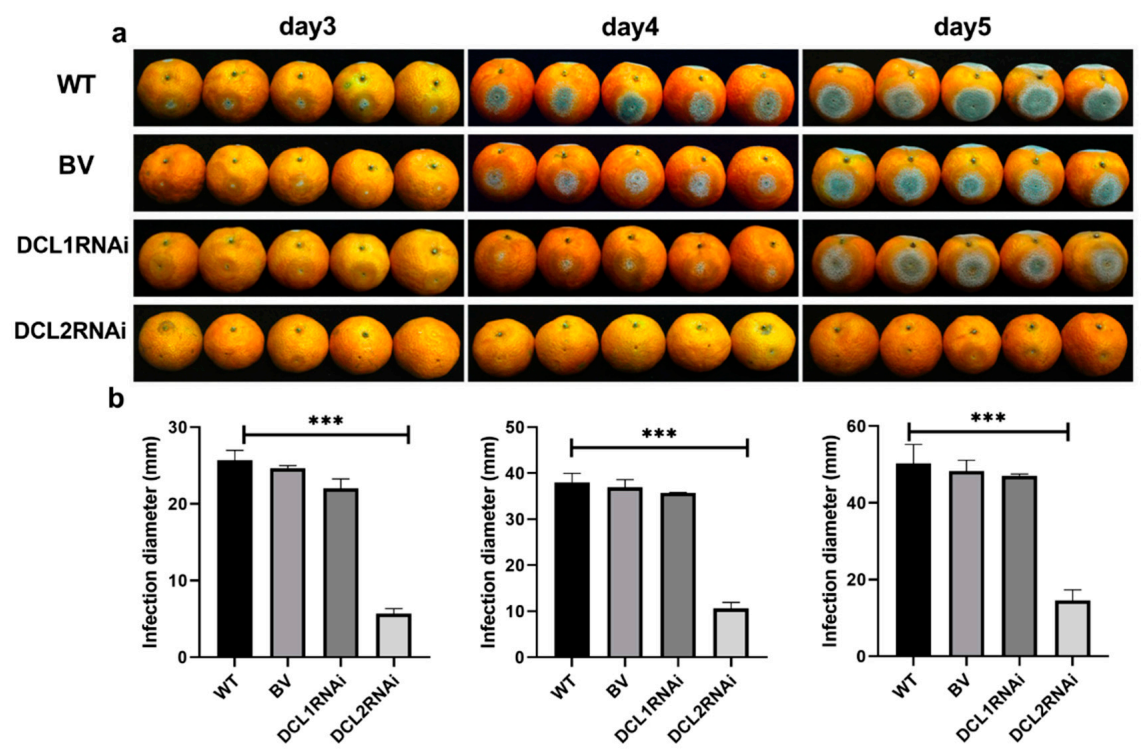

Figure 2. (a) Images of the infection of citrus fruits by P. italicum; (b) infection diameter on the surface of the citrus fruits 3, 4, and 5 days after inoculation. WT (wild-type), BV (blank vector transformant), DCL1RNAi (Dicer-like 1 gene transformant), and DCL2RNAi (Dicer-like 2 gene transformant). Each bar represents a mean \pm standard error $(n=3)$, and the asterisk indicates a significant difference $\left.{ }^{* * *}, p<0.001\right)$.

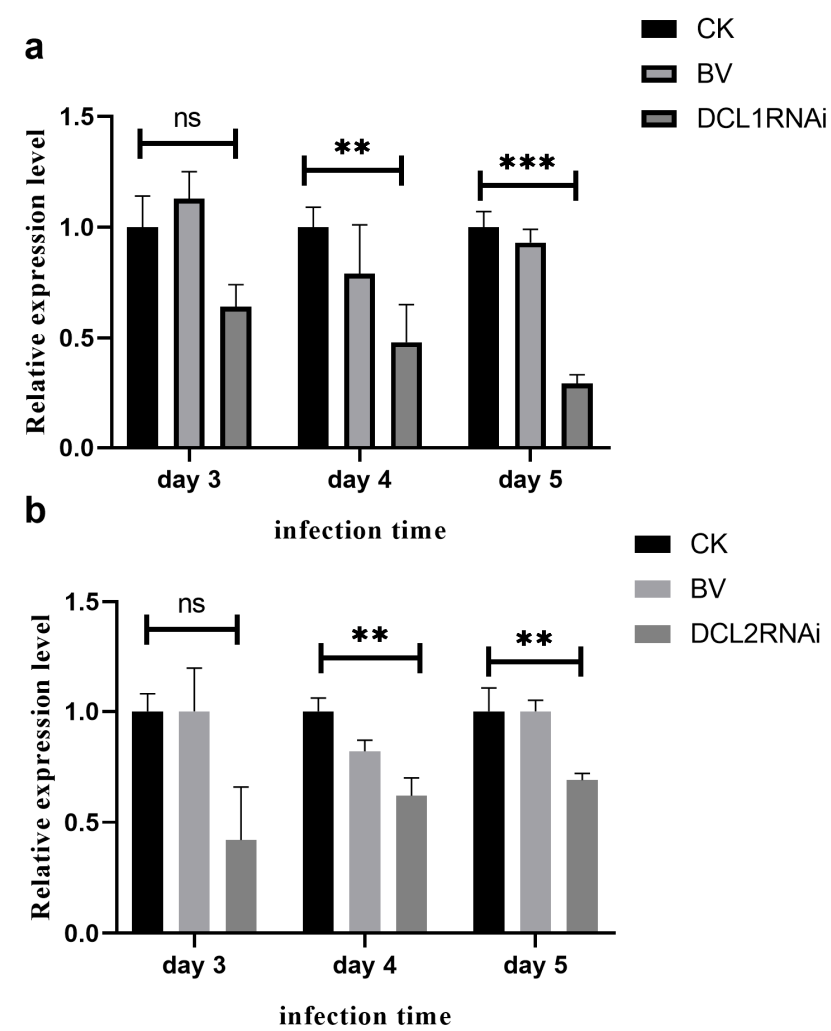

Figure 3. qRT-PCR expression analysis of the Dicer1-like gene (a) and Dicer2-like gene (b) in P. italicum after inoculation on citrus fruit epidermis for 3, 4, and 5 days. CK (wild-type), BV (blank vector transformant), DCL1RNAi (Dicer-like 1 gene transformant), and DCL2RNAi (Dicer-like 2 gene transformant). Each bar represents a mean \pm standard error $(n=3)$, and the asterisk indicates a significant difference $\left({ }^{* *}, p<0.01,{ }^{* * *}, p<0.001\right)$, no significance (ns). 


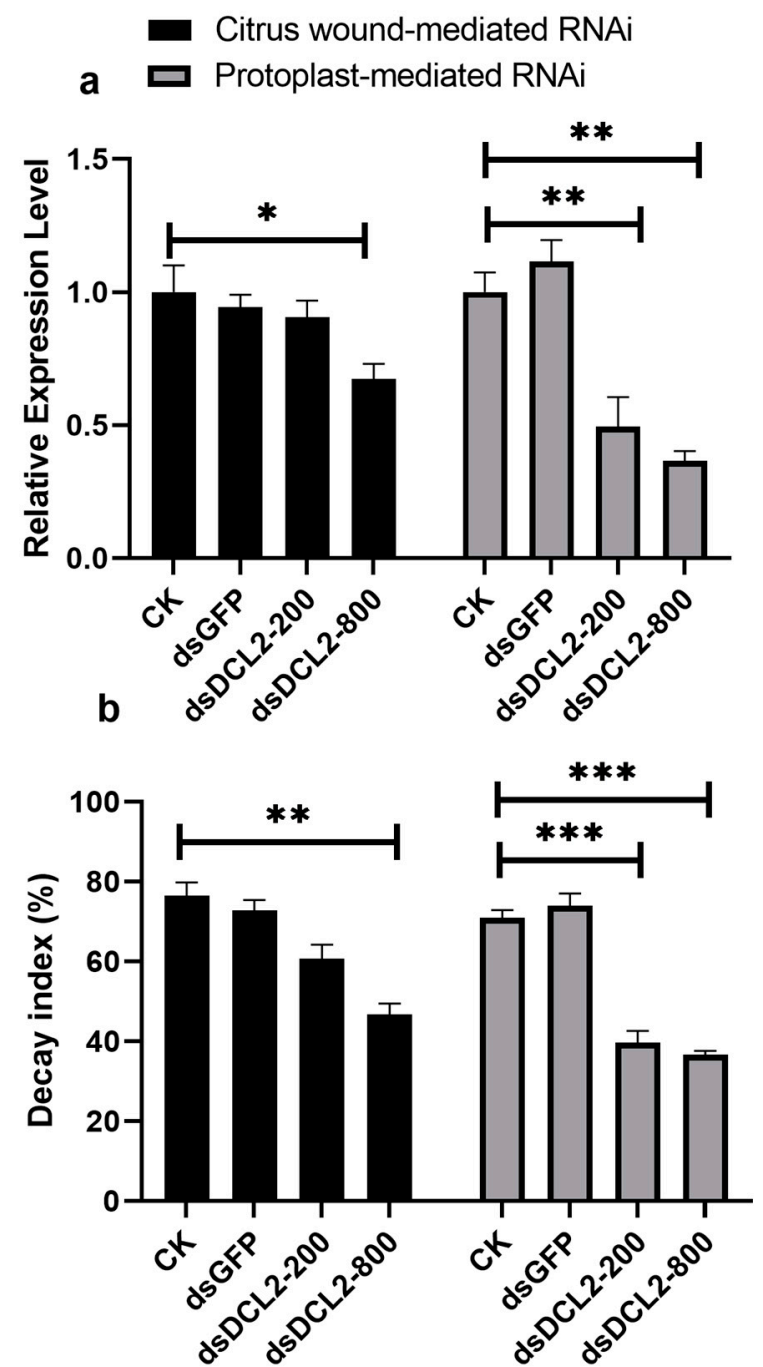

Figure 4. Effects of citrus wound-mediated RNAi and protoplast-mediated RNAi on the expression profile of the Pit-DCL2 gene (a) and the citrus decay index caused by wild-type P. italicum infection (b). dsDCL2-200 and 800 mean the concentration of the treated dsRNA is $200 \mathrm{ng}$ and $800 \mathrm{ng}$, respectively. Each bar represents a mean \pm standard error $(n=3)$, and the asterisk indicates a significant difference $\left({ }^{*}, p<0.5,{ }^{* *}, p<0.01,{ }^{* * *}, p<0.001\right)$.

\subsection{Characterization of Small RNAs in the RNAi Transformants}

We sequenced nine sRNA libraries prepared from the DCL1RNAi and DCL2RNAi transformants as well as the wild-type strain by using an Illumina platform. A total number of raw reads (115.77 millions), ranging from 10.89 to 15.41 million reads, were generated from the nine individual libraries (Table S2). After adapter removal and quality filtering, a total of 110.77 million clean reads were used for further analysis; the clean reads with lengths of 18-35 nt were termed total sRNA (69.88 million). The total sRNA was observed to have $64.75-83.49 \%$ of reads mapping to the referenced P. italicum genome (Table S2). The mapped total sRNA was further classified according to the origin from different genomic regions, and the classification suggested that the valid sRNA was mainly produced from noncoding RNA species, including rRNA, tRNA, and snRNA (Figure 5b). However, the percentage of the sRNA matching rRNA and exon sequences was greatly reduced in the DCL2RNAi and DCL1RNAi samples compared to that in the wild-type samples (Figure $5 b$ ). In addition, the size distribution of the sRNA showed a peak at 19-21 nt and 21-23 nt in both the wild-type and the DCL1RNAi mutant, but the peaks were shifted to 21-23 nt and 23-25 nt in the DCL2RNAi mutant (Figure 5a), and preferential 
accumulation of 5'-U (uracil) sRNA was found in both the wild-type strain and the RNAi mutant transformants (Figure 5c).

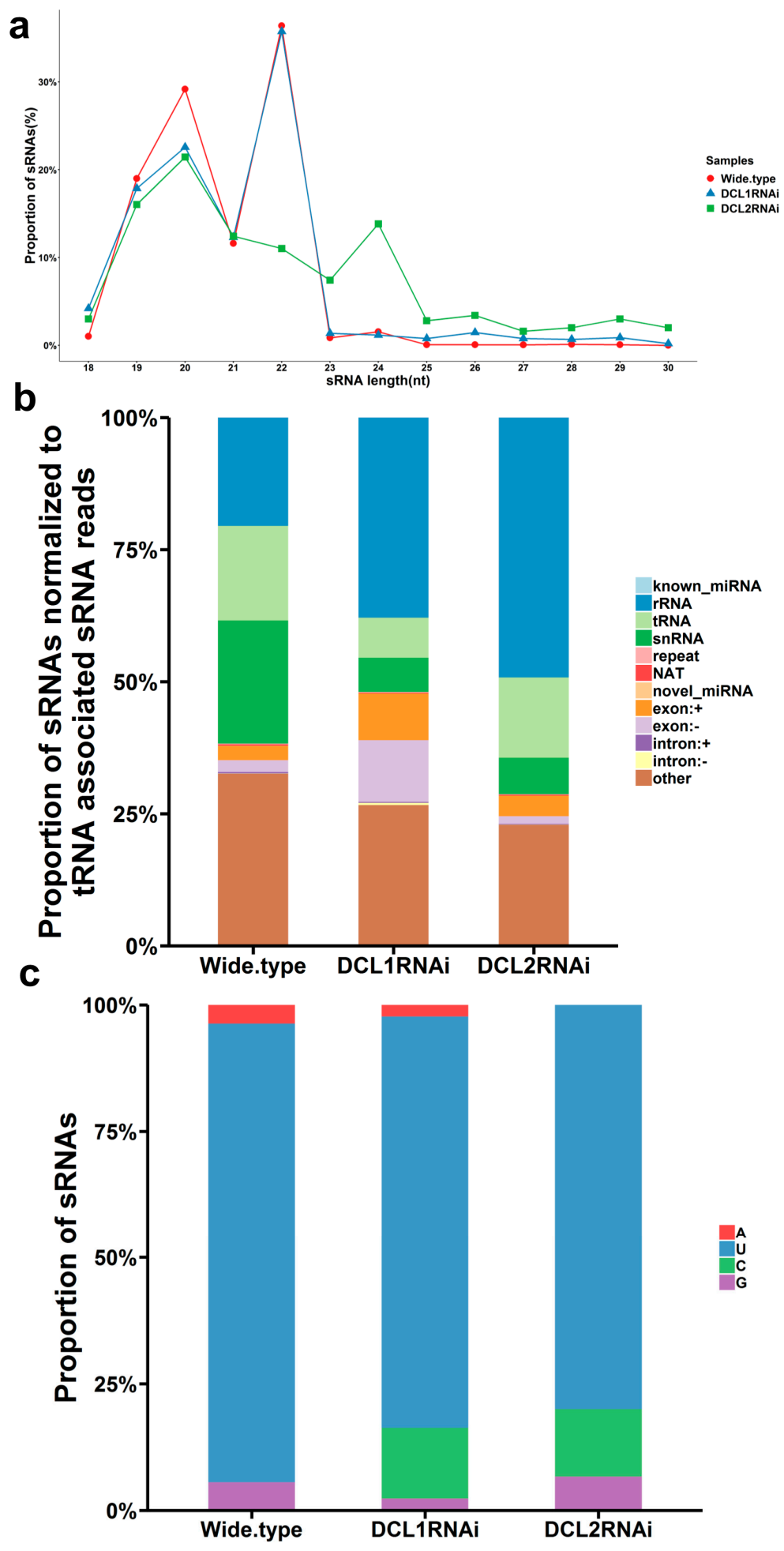

Figure 5. Characteristics of the small RNAs (sRNAs) in different samples. (a) Size distribution of sRNA from wild-type P. italicum and the RNAi transformants. (b) Proportion of total genome-matched sRNA from wild-type P. italicum and the RNAi transformants. (c) $5^{\prime}$ Nucleotide preference for sRNAs in wild-type P. italicum and the RNAi transformants. 


\subsection{Structural Features, Expression Patterns and Predicted Targets of the Novel Pit-milRNAs}

As there is no currently available miRNA database for fungal species, we used miRNA sequences published in miRBase database to search the known miRNAs in the sequenced libraries, which revealed 15 known miRNAs in P. italicum (Table S3). However, we performed a prediction of the novel miRNAs in the sequenced libraries, and the results identified a total of 12 novel milRNAs (microRNA-like RNAs), among which Pit-novel 7 had the lowest MFE (minimum free energy), suggesting good structural stability. The stem-loop structures of these milRNAs were predicted by RNAfold (Figure S1). On average, the number of novel milRNAs was significantly reduced in the RNAi transformants compared to that of the wild-type strain; in addition, novel milRNAs (Pit-novel 6 and Pit-novel 7) were found in DCL1RNAi and the wild type, but not in DCL2RNAi (Figure 6a). Primers covering the complete precursor sequences of the Pit-milRNAs were designed to perform expression analysis via RT-qPCR. Five of the primer pairs worked well, and the results showed that the precursor sequences of miRNAs (Pit-novel 2, 6, 7 and 11) accumulated in the RNAi transformants (Figure 6b), suggesting that the cleavage ability of Dicer was weakened in the RNAi transformants. However, we only detected one of the milRNA candidates (Pit-novel 7) by Northern blotting, which showed an increased amount of the precursor sRNA and a decreased amount of the mature sRNA in the RNAi transformants compared to the wild-type strain (Figure 6c), consistent with the expected results. Nevertheless, we failed to detect other Pit-milRNAs, which may be caused by an insufficient abundance of the sRNAs under the culture conditions. Among these Pit-milRNAs, four were predicted to have five functionally annotated target genes in C. sinensis, and Pit-novel 7 was predicted to originate from a locus in contig1283 at the antisense gene link region between 115,664 and 115,928. Further, Pit-novel 7 milRNA was found to have one target in the $C$. sinensis genome, which was annotated as an AP2/B3-like transcription factor (Table 1).
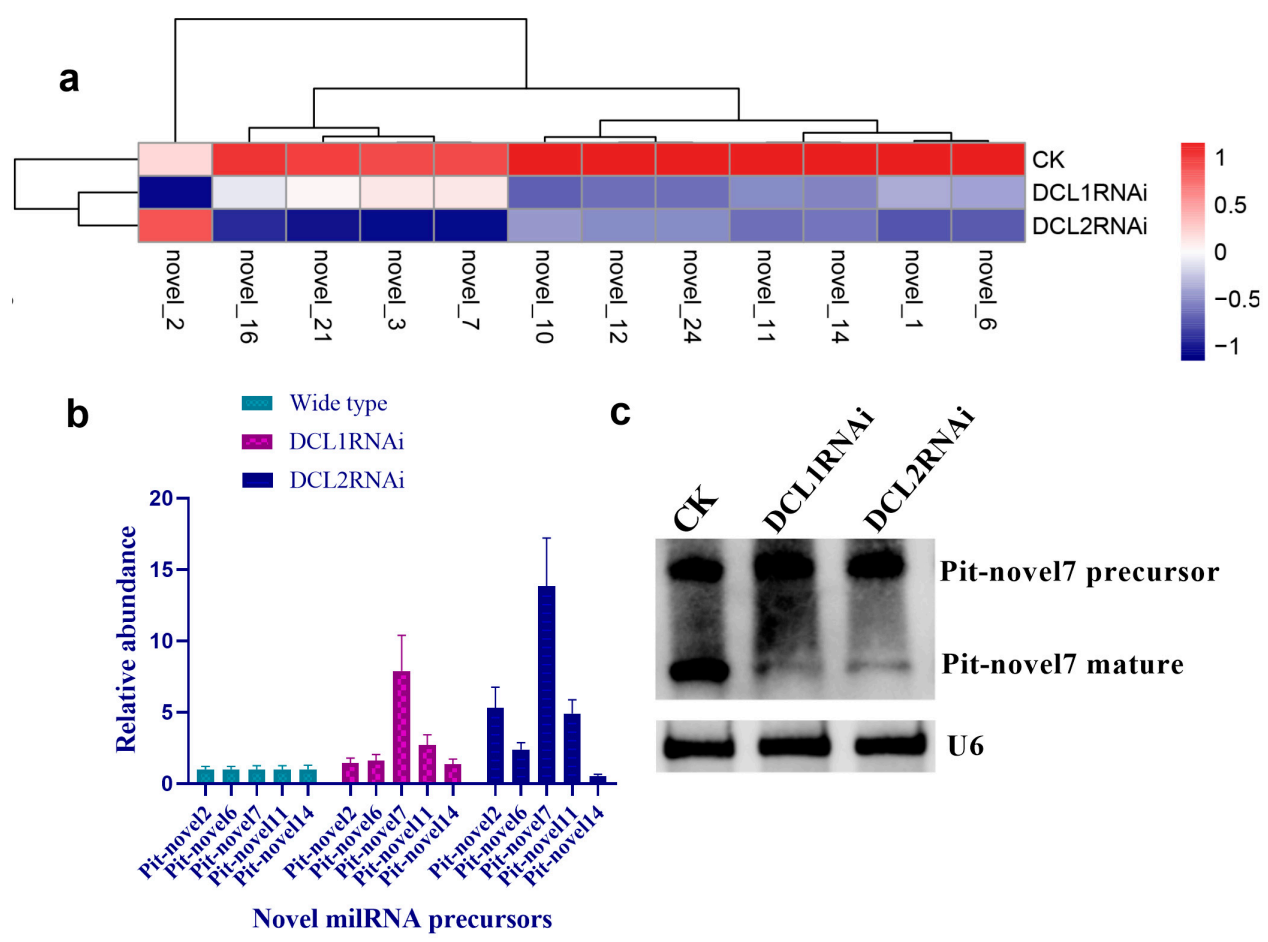

Figure 6. Characteristics of novel microRNA-like RNAs (milRNAs) in P. italicum. Heatmap of the differentially expressed milRNAs based on small RNA sequencing (a). RT-qPCR analysis of the precursors of the novel milRNA precursors (b). Northern blot analysis of Pit-novel7 milRNA, and U6 was used as an internal reference (c). 
Table 1. Characteristics of the predicted novel milRNAs and their targets in Citrus sinensis.

\begin{tabular}{|c|c|c|c|c|c|c|}
\hline Mature_ID & Mature_Seq & Precursor Position & MFE & Target Accession & Target Annotation & Alignment \\
\hline Pit-novel1 & $\begin{array}{l}\text { ugccaaaguaguug } \\
\text { gacucgcu }\end{array}$ & contig333:14656..14796:+ & -50.4 & $\begin{array}{l}\text { Cs7g21420 } \\
\text { Cs7g21400 }\end{array}$ & $\begin{array}{l}\text { Leucine-rich repeat (LRR) } \\
\text { receptor kinase } \\
\text { MDIS1-interacting receptor } \\
\text { like kinase 2 }\end{array}$ & 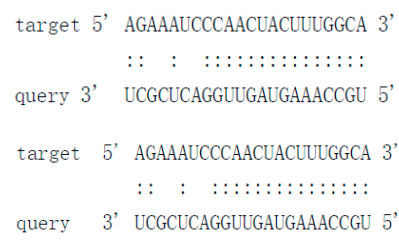 \\
\hline Pit-novel2 & $\begin{array}{l}\text { uaauugauccegc } \\
\text { uugcucccacg }\end{array}$ & contig2630:133598..133733:+ & -75.9 & N/A & N/A & \\
\hline Pit-novel3 & $\begin{array}{l}\text { uauggugacaaaa } \\
\text { ggcuucauu }\end{array}$ & contig1137:40522..40624:- & -49.8 & N/A & N/A & \\
\hline Pit-novel6 & $\begin{array}{l}\text { uacguagcagcg } \\
\text { auccucuagc }\end{array}$ & contig837:270..404:+ & -43.7 & N/A & N/A & \\
\hline Pit-novel7 & $\begin{array}{l}\text { uggcuggagcau } \\
\text { gcgcuugauu }\end{array}$ & contig1283:115664..115928:- & -90.6 & Cs7g19510 & $\begin{array}{l}\text { AP2/B3-like transcriptional } \\
\text { factor }\end{array}$ & 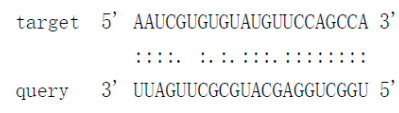 \\
\hline Pit-novel10 & $\begin{array}{l}\text { ugggaccuccg } \\
\text { aaguauucgg }\end{array}$ & contig80:152579..152678:+ & -61.14 & N/A & N/A & \\
\hline Pit-novel11 & $\begin{array}{l}\text { uuugggugauu } \\
\text { uucaggcuc }\end{array}$ & contig988:35989..36189:+ & -77.72 & Cs4g07930 & Subtilisin-like protease & 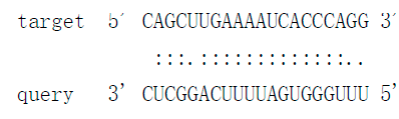 \\
\hline Pit-novel12 & $\begin{array}{l}\text { uacuucggagg } \\
\text { ucccacugu }\end{array}$ & contig2212:6256..6357:- & -64.1 & N/A & N/A & \\
\hline Pit-novel14 & $\begin{array}{l}\text { ugaguaggaga } \\
\text { gucauuugcu }\end{array}$ & contig769:62932..63030:+ & -51.3 & Cs7g09590 & $\begin{array}{l}\text { Protein-tyrosine-phosphatase } \\
\text { MKP1-like isoform X1 }\end{array}$ & 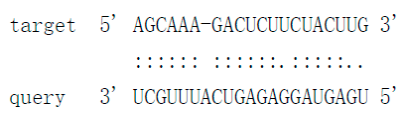 \\
\hline Pit-novel16 & $\begin{array}{l}\text { uaugacgauac } \\
\text { ugcuccauac }\end{array}$ & contig1182:333..382:+ & -17.1 & N/A & N/A & \\
\hline Pit-novel21 & $\begin{array}{l}\text { uggugacaaaa } \\
\text { ggcuucauuuu }\end{array}$ & contig50:167259..167366:- & -44.9 & N/A & N/A & \\
\hline Pit-novel24 & $\begin{array}{l}\text { uacuucggagg } \\
\text { ucccacuguacga }\end{array}$ & contig840:52392..52496:+ & -65.4 & N/A & N/A & \\
\hline
\end{tabular}

Note: N/A (not applicable), MFE (minimum free energy), Pit (Penicillium italicum). 


\section{Discussion}

P. italicum is responsible for serious economic losses of citrus fruits during postharvest storage and transportation. Currently, the application of synthetic fungicides is the major method for controlling the postharvest citrus pathogens, but those fungicides have shown limited success. Therefore, an alternative strategy is required. In the field of life science, although RNAi technology is not the most efficient tool for the functional characterization of novel genes compared to approaches such as CRISPER-Cas9 technology, it has emerged as the alternative strategy with the greatest potential to control agricultural pests in a way that blocks gene expression [31]. However, this novel strategy is required to widely characterize pathogenesis-related genes in filamentous fungi [32]. Our findings demonstrated that the Pit-DCL2 gene is a primary contributor to pathogenesis (Figure 2) and also showed the biosynthesis and size distribution of sRNAs in P. italicum (Figure 5). This result was consistent with previous reports on the plant pathogenic fungi $V$. mali [12] and Colletotrichum gloeosporioides [13], suggesting that this gene may be a potential target for the RNAi-based control of fungal diseases. Indeed, external spray application of dsRNA targeting fungal DCL-like genes significantly inhibited the development of gray mold disease in different fruits and vegetables [33].

The efficiency of dsRNA application on the surface of citrus fruits could be improved by increasing the amount of dsRNA. As shown in Figure 4, the application of $800 \mathrm{ng}$ dsDCL2 had a higher efficiency than that of $200 \mathrm{ng}$ dsDCL2 in citrus wound-medicated RNAi. This approach includes a key step of incubating dsRNA with citrus wounds, which achieved a gene silencing efficiency similar to that of incubating dsRNA with P. italicum protoplasts (Figure 4); doing this incubation before the infection is also a key step in protoplast-mediated RNAi. Indeed, protoplast-mediated RNAi without the barrier of the fungal cell wall has proven to be immensely successful in filamentous fungi [34,35]. It is accepted that exosomes (extracellular vesicles) play a central role in cell-to-cell communication, for example, Arabidopsis secretes exosome-like extracellular vesicles to deliver sRNA into Botrytis cinerea to silence virulence-related genes [7], and exosomes are involved in the transfer of small RNAs by nematode parasites to mammalian cells [36]. Citrus wound-derived vesicles might play key roles in transferring dsRNA into fungal cells, and if so, citrus exosomes are likely to be employed in exogenous dsRNA-mediated RNAi for the development of fungicides against $P$. italicum. Indeed, grapefruit-derived nanovesicles can transport siRNAs to different types of mammalian cells [37]. In contrast to siRNA amplification in fungi, siRNAs in Caenorhabditis elegans can efficiently develop into substantial amounts of siRNAs by promoting secondary siRNA amplification [38]. There is currently no evidence to show that fungi have the ability to maintain secondary siRNA amplification in vitro, although dsRNAs being dripped onto plant surfaces may induce the plant RNAi machinery to amplify fungal dsRNA. Our results are consistent with the silencing of Myo5 in Fusarium asiaticum via spray-induced gene silencing, which shows an increased efficiency of dsRNA uptake via the wounded plant surface [39]. However, dsRNA surface treatment may be hard to protect non-wounded citrus against $P$. italicum, but we think that the composition of the dsRNA preparation may be improved by adding citrus exosomes.

Cross-kingdom RNAi (ck-RNAi) is considered to be a natural phenomenon by which sRNAs are transferred between host and pathogens and has not only provided significant new insights into the pathogenic mechanisms of plant pathogens, but has also opened a new avenue to generate environmentally friendly fungicides $[40,41]$. While natural ck-RNAi has attracted great interest in theoretical and applied studies underlying host-pathogen interactions and approaches for managing plant pathogens, surprisingly, only a few studies have been reported in the literature. There are two well-documented examples of natural ck-RNAi: Botrytis cinerea Bc-siR37 suppresses plant defense genes, including At-WRKY7, At-PMR6, and At-FEI2 [42], and Puccinia striiformis Pst-milR1 acts as an effector to suppress host immunity by binding the wheat $P R 2$ gene [43]. However, Kettles et al. recently confirmed the lack of evidence for ck-RNAi during the wheat-Zymoseptoria tritici interaction [44]. Currently, our understanding of natural ck-RNAi is still in the initial stage, and additional research studies will promote the development of this field. DCLs are the most important components of the 
RNAi machinery in eukaryotes, and in the present study, downregulation of the DCL2-like gene was revealed, but the DCL1-like gene in P. italicum did not significantly reduce in its ability to infect citrus fruits (Figures 2 and 3). Subsequent sRNA sequencing also indicated that the DCL2-like gene plays a more important role in regulating milRNA expression than the DCL1-like gene in P. italicum (Figure 6), as similarly reported in Magnaporthe oryzae [45]. These data suggest that $P$. italicum may possess a mechanism of RNAi or ck-RNAi and that its sRNA might be an effector in citrus epidermal cells that induces the RNAi response of citrus fruits during the infection process.

Furthermore, we predicted 12 novel sRNA precursors with a microRNA-like stem-loop secondary structure in the P. italicum sRNA libraries (Figure S1). In addition, a high-throughput in silico data analysis revealed 24 potential candidate milRNAs in Penicillium marneffei [46] and 34 in Penicillium chrysogenum [47]. Why did we identify a small amount of novel milRNAs in P. italicum? The reason may be that the collected $P$. italicum samples were not at different developmental stages or at the infectious stage in the citrus fruit. It has been reported that Pt-sRNA can be especially accumulated in Penicillium triticina-infected wheat leaf tissue [48] and that a number of Blumeria graminis sRNAs were significantly differentially expressed at 0 to $48 \mathrm{~h}$ after inoculation in barley [18]. These findings reflect that internal needs or environmental stresses might form a feedback regulation mechanism to stimulate the accumulation of sRNAs in fungi or oomycetes.

In fact, the number of sRNA candidates, in particular those with the potential for cross-kingdom transfer, is rather limited, so it is hard to overcome the huge number of plant immune-related genes. Moreover, we considered that only some sRNAs can travel across the boundaries between plant pathogens and their hosts to silence genes in the interacting plant hosts, while most of the remaining sRNAs function endogenously. However, we have to point out that most fungal sRNAs, although they do not contain a typical hairpin structure, may also be functional in inducing RNAi during plant-microbe interactions as well as during the process of their own growth and development. In filamentous fungi, the dicer-dependent RNAi process is recognized to generate two types of sRNA, namely, miRNA, and siRNA. Many studies have demonstrated that most sRNA should exist with structural features of siRNA. A total of 1-1.28 million potential sRNAs and only two candidate milRNAs were identified by using Illumina sequencing in P. triticina [48]. A total of 600-700 sRNAs were obtained from Trichoderma reesei by Solexa sequencing, but only 13 milRNAs were predicted based on hairpin structure analysis [49]. Indeed, dsRNA/siRNA from a vector expressing the transgene construct also worked well, with specific efficiency to silence related genes in fungi [34,35]. Consequently, we need to develop a pipeline to identify siRNA production and a reliable methodology to experimentally characterize functions of siRNAs in fungal species in the future.

Considering that natural ck-RNAi must show the evidence of the potential target genes in the host, we predicted the targets of the 12 novel Pit-milRNAs against the Citrus sinensis genome by using TargetFinder 1.6. Interestingly, we found that all of the putative target genes play critical roles in plant innate immunity or the biotic stress response (Table 1); for example, Pit-novel 1 targets a host gene encoding a leucine-rich repeat (LRR) receptor kinase, which is the largest subgroup of the receptor-like kinase family and functions as the first barrier in the plant innate immunity to recognize potential invaders [50]. Subtilisin-like proteases, targeted by Pit-novel 11, are also receptors associated with plant-pathogen recognition and immune priming [51]. These findings suggest that natural ck-RNAi is a potential virulence mechanism involved in interactions between citrus fruits and P. italicum. However, the direct interactions between Pit-milRNAs and their target host genes are unclear, and this knowledge will depend on technological advances in the future.

\section{Conclusions}

Understanding the molecular mechanism of ck-RNAi will help us to develop innovative strategies for crop protection. This purpose motivates us to explore the RNAi machinery and the biogenesis and function of sRNA in P. italicum. As revealed in this study, Pit-DCL2-mediated sRNA may play an important role in P. italicum pathogenicity. In addition, a method for direct exogenous application 
of dsDCL2 molecules was developed, based on citrus wound-mediated RNAi and showed great potential to trigger RNAi in P. italicum. Hence, for the first time, we illustrated that exogenous dsRNA application can be used to control diseases in postharvest citrus fruits.

Supplementary Materials: The following are available online at http://www.mdpi.com/2073-4409/9/2/363/s1, Figure S1: The putative secondary structures of precursors of Pit-novel milRNAs based on RNAfold web server (http://rna.tbi.univie.ac.at/cgi-bin/RNAWebSuite/RNAfold.cgi); mature sRNAs are shown in red, Table S1: Primer sequences used in this study, Table S2: Analysis of small RNA-seq data, Table S3: Summary of putative known miRNAs in the sequenced libraries.

Author Contributions: Conceptualization, Y.J., Y.S. and L.G.; Data curation, C.Y. and L.G.; Formal analysis, H.Z. and L.G.; Funding acquisition, Y.J. and L.G.; Investigation, C.Y. and L.G.; Methodology, C.Y. and L.G. All authors have read and agreed to the published version of the manuscript.

Funding: Financial support for this research was provided by the National Natural Science Foundation of China (No. 31772033), Pearl River Science and Technology New Star Fund of Guangzhou (No. 201710010135), Guangdong Provincial Agricultural Department Project for Rural Revitalization (No. 2018LM2177), and Foundation of CAS Key Laboratory of Plant Resource Conservation and Sustainable Utilization (Y821171001).

Conflicts of Interest: The authors declare no conflict of interest.

\section{References}

1. FAOSTAT Database. Available online: http://www.fao.org/faostat/en (accessed on 1 October 2017).

2. Papoutsis, K.; Mathioudakis, M.M.; Hasperué, J.H.; Ziogas, V. Non-chemical treatments for preventing the postharvest fungal rotting of citrus caused by Penicillium digitatum (green mold) and Penicillium italicum (blue mold). Trends Food Sci. Technol. 2019, 86, 479-491. [CrossRef]

3. Prusky, D.; McEvoy, J.L.; Saftner, R.; Conway, W.S.; Jones, R. Relationship Between Host Acidification and Virulence of Penicillium spp. on Apple and Citrus Fruit. Phytopathology 2004, 94, 44-51. [CrossRef] [PubMed]

4. Macarisin, D.; Cohen, L.; Eick, A.; Rafael, G.; Belausov, E.; Wisniewski, M.; Droby, S. Penicillium digitatum Suppresses Production of Hydrogen Peroxide in Host Tissue During Infection of Citrus Fruit. Phytopathology 2007, 97, 1491-1500. [CrossRef] [PubMed]

5. Li, B.; Zong, Y.; Du, Z.; Chen, Y.; Zhang, Z.; Qin, G.; Zhao, W.; Tian, S. Genomic Characterization Reveals Insights Into Patulin Biosynthesis and Pathogenicity in Penicillium Species. Mol. Plant Microbe Interact. 2015, 28, 635-647. [CrossRef]

6. Ballester, A.R.; Marcet-Houben, M.; Levin, E.; Sela, N.; Selma-Lázaro, C.; Carmona, L.; Wisniewski, M.; Droby, S.; González-Candelas, L.; Gabaldón, T. Genome, Transcriptome, and Functional Analyses of Penicillium expansum Provide New Insights Into Secondary Metabolism and Pathogenicity. Mol. Plant Microbe Interact. 2015, 28, 232-248. [CrossRef]

7. Cai, Q.; He, B.; Kogel, K.H.; Jin, H. Cross-kingdom RNA trafficking and environmental RNAi-nature's blueprint for modern crop protection strategies. Curr. Opin. Microbiol. 2018, 46, 58-64. [CrossRef]

8. Nakayashiki, H.; Kadotani, N.; Mayama, S. Evolution and diversification of RNA silencing proteins in fungi. J. Mol. Evol. 2006, 63, 127-135. [CrossRef]

9. Carmell, M.A.; Xuan, Z.; Zhang, M.Q.; Hannon, G.J. The Argonaute family: Tentacles that reach into RNAi, developmental control, stem cell maintenance, and tumorigenesis. Genes Dev. 2002, 16, 2733-2742. [CrossRef]

10. Dang, Y.; Yang, Q.; Xue, Z.; Liu, Y. RNA interference in fungi: Pathways, functions, and applications. Eukaryot. Cell 2011, 10, 1148-1155. [CrossRef]

11. Meng, H.; Wang, Z.; Wang, Y.; Zhu, H.; Huang, B. Dicer and Argonaute Genes Involved in RNA Interference in the Entomopathogenic Fungus Metarhizium robertsii. Appl. Environ. Microbiol. 2017, 83, e03230. [CrossRef]

12. Feng, H.; Xu, M.; Liu, Y.; Dong, R.; Gao, X.; Huang, L. Dicer-Like Genes Are Required for $\mathrm{H} 2 \mathrm{O} 2$ and $\mathrm{KCl}$ Stress Responses, Pathogenicity and Small RNA Generation in Valsa mali. Front. Microbiol. 2017, 8, 1166. [CrossRef] [PubMed]

13. Wang, Q.; An, B.; Hou, X.; Guo, Y.; Luo, H.; He, C. Dicer-like Proteins Regulate the Growth, Conidiation, and Pathogenicity of Colletotrichum gloeosporioides from Hevea brasiliensis. Front. Microbiol. 2018, 8, 2621. [CrossRef] [PubMed]

14. Romano, N.; Macino, G. Quelling: Transient inactivation of gene expression in Neurospora crassa by transformation with homologous sequences. Mol. Microbiol. 1992, 6, 3343-3353. [CrossRef] 
15. Wang, L.; Xu, X.; Yang, J.; Chen, L.; Liu, B.; Liu, T.; Jin, Q. Integrated microRNA and mRNA analysis in the pathogenic filamentous fungus Trichophyton rubrum. Bmc Genom. 2018, 19, 933. [CrossRef]

16. Derbyshire, M.; Mbengue, M.; Barascud, M.; Navaud, O.; Raffaele, S. Small RNAs from the plant pathogenic fungus Sclerotinia sclerotiorum highlight host candidate genes associated with quantitative disease resistance. Mol. Plant Pathol. 2019, 20, 1279-1297. [CrossRef] [PubMed]

17. Zhao, M.; Ji, H.M.; Gao, Y.; Cao, X.X.; Mao, H.Y.; Ouyang, S.Q.; Liu, P. An integrated analysis of mRNA and sRNA transcriptional profiles in tomato root: Insights on tomato wilt disease. PLoS ONE 2018, 13, e0206765. [CrossRef] [PubMed]

18. Hunt, M.; Banerjee, S.; Surana, P.; Liu, M.; Fuerst, G.; Mathioni, S.; Meyers, B.C.; Nettleton, D.; Wise, R.P. Small RNA discovery in the interaction between barley and the powdery mildew pathogen. BMC Genom. 2019, 20, 610 .

19. Feng, H.; Xu, M.; Zheng, X.; Zhu, T.; Gao, X.; Huang, L. microRNAs and Their Targets in Apple (Malus domestica cv. "Fuji") Involved in Response to Infection of Pathogen Valsa mali. Front. Plant Sci. 2017, 8, 2081. [CrossRef]

20. Carthew, R.W.; Sontheimer, E.J. Origins and Mechanisms of miRNAs and siRNAs. Cell 2009, 136, 642-655. [CrossRef]

21. Ma, X.; Tang, Z.; Qin, J.; Meng, Y. The use of high-throughput sequencing methods for plant microRNA research. RNA Biol. 2015, 12, 709-719. [CrossRef]

22. Gong, L.; Tan, H.; Chen, F.; Li, T.; Zhu, J.; Jian, Q.; Yuan, D.; Xu, L.; Hu, W.; Jiang, Y.; et al. Novel synthesized 2, 4-DAPG analogues: Antifungal activity, mechanism and toxicology. Sci. Rep. 2016, 6, 32266. [CrossRef] [PubMed]

23. Chen, X.; Li, L.; Hu, Q.; Zhang, B.; Wu, W.; Jin, F.; Jiang, J. Expression of dsRNA in recombinant Isaria fumosorosea strain targets the TLR7 gene in Bemisia tabaci. BMC Biotechnol. 2015, 15, 64. [CrossRef] [PubMed]

24. Visser, M.; Gordon, T.R.; Wingfield, B.D.; Wingfield, M.J.; Viljoen, A. Transformation of Fusarium oxysporum f. sp cubense, causal agent of Fusarium wilt of banana, with the green fluorescent protein (GFP) gene. Australas Plant Pathol 2004, 33, 69-75. [CrossRef]

25. Proctor, R.H.; Desjardins, A.E.; Plattner, R.D.; Hohn, T.M. A polyketide synthase gene required for biosynthesis of fumonisin mycotoxins in Gibberella fujikuroi slating population A. Fungal Genet. Biol. 1999, 27, 100-112. [CrossRef]

26. Wen, M.; Shen, Y.; Shi, S.; Tang, T. miREvo: An Integrative microRNA Evolutionary Analysis Platform for Next-generation Sequencing Experiments. BMC Bioinform. 2010, 13, 140. [CrossRef]

27. Friedlander, M.R.; Mackowiak, S.D.; Li, N.; Chen, W.; Rajewsky, N. miRDeep2 accurately identifies known and hundreds of novel microRNA genes in seven animal clades. Nucleic Acids Res. 2011, 40,37-52. [CrossRef]

28. Denman, R.B. Using RNAFOLD to predict the activity of small catalytic RNAs. Biotechniques 1993, 15, 1090-1095.

29. Dai, X.B.; Zhuang, Z.H.; Zhao, P.X. psRNATarget: A plant small RNA target analysis server (2017 release). Nucleic Acids Res. 2018, 46, W49-W54. [CrossRef]

30. Livak, K.J.; Schmittgen, T.D. Analysis of relative gene expression data using Real-Time quantitative PCR and the $2^{-\Delta \Delta C T}$ Method. Methods 2001, 25, 402-408. [CrossRef]

31. Zotti, M.; Dos Santos, E.A.; Cagliari, D.; Christiaens, O.; Taning, C.N.T.; Smagghe, G. RNA interference technology in crop protection against arthropod pests, pathogens and nematodes. Pest Manag. Sci. 2018, 74, 1239-1250. [CrossRef]

32. Machado, A.K.; Brown, N.A.; Urban, M.; Kanyuka, K.; Hammond-Kosack, K.E. RNAi as an emerging approach to control Fusarium head blight disease and mycotoxin contamination in cereals. Pest Manag. Sci. 2018, 74, 790-799. [CrossRef] [PubMed]

33. Wang, M.; Weiberg, A.; Lin, F.M.; Thomma, B.P.; Huang, H.D.; Jin, H. Bidirectional cross-kingdom RNAi and fungal uptake of external RNAs confer plant protection. Nat. Plants 2016, 2, 16151. [CrossRef] [PubMed]

34. Pan, Y.; Ye, T.; Gao, Z. Cloning and functional analysis of succinate dehydrogenase gene PsSDHA in Phytophthora sojae. Microb. Pathog. 2017, 108, 40-48. [CrossRef]

35. Enayati, S.; Azizi, M.; Aminollahi, E.; Ranjvar Shahrivar, M.; Khalaj, V. T7-RNA polymerase dependent RNAi system in Aspergillus fumigatus: A proof of concept study. FEMS Microbiol. Lett. 2016, 363, fnw029. [CrossRef] [PubMed] 
36. Buck, A.H.; Coakley, G.; Simbari, F.; McSorley, H.J.; Quintana, J.F.; Le Bihan, T.; Kumar, S.; Abreu-Goodger, C.; Lear, M.; Harcus, Y.; et al. Exosomes secreted by nematode parasites transfer small RNAs to mammalian cells and modulate innate immunity. Nat. Commun. 2014, 5, 5488. [CrossRef]

37. Wang, Q.; Zhuang, X.; Mu, J.; Deng, Z.B.; Jiang, H.; Zhang, L.; Xiang, X.; Wang, B.; Yan, J.; Miller, D.; et al. Delivery of therapeutic agents by nanoparticles made of grapefruit-derived lipids. Nat. Commun. 2013, 4, 1867. [CrossRef]

38. Zhang, C.; Montgomery, T.A.; Fischer, S.E.; Garcia, S.M.; Riedel, C.G.; Fahlgren, N.; Sullivan, C.M.; Carrington, J.C.; Ruvkun, G. The Caenorhabditis elegans RDE-10/RDE-11 complex regulates RNAi by promoting secondary siRNA amplification. Curr. Biol. 2012, 22, 881-890. [CrossRef]

39. Song, X.S.; Gu, K.X.; Duan, X.X.; Xiao, X.M.; Hou, Y.P.; Duan, Y.B.; Wang, J.X.; Yu, N.; Zhou, M.G. Secondary amplification of siRNA machinery limits the application of spray-induced gene silencing. Mol. Plant Pathol. 2018, 19, 2543-2560. [CrossRef]

40. Wang, M.; Thomas, N.; Jin, H. Cross-kingdom RNA trafficking and environmental RNAi for powerful innovative pre- and post-harvest plant protection. Curr. Opin. Plant Biol. 2017, 38, 133-141. [CrossRef]

41. Zeng, J.; Gupta, V.K.; Jiang, Y.; Yang, B.; Gong, L.; Zhu, H. Cross-Kingdom Small RNAs Among Animals, Plants and Microbes. Cells 2019, 8, 371. [CrossRef]

42. Wang, M.; Weiberg, A.; Dellota, E.J.; Yamane, D.; Jin, H. Botrytis small RNA Bc-siR37 suppresses plant defense genes by cross-kingdom RNAi. RNA Biol. 2017, 14, 421-428. [CrossRef] [PubMed]

43. Wang, B.; Sun, Y.; Song, N.; Zhao, M.; Liu, R.; Feng, H.; Wang, X.; Kang, Z. Puccinia striiformis f. sp tritici microRNA-like RNA 1 (Pst-milR1), an important pathogenicity factor of Pst, impairs wheat resistance to Pst by suppressing the wheat pathogenesis-related 2 gene. New Phytol 2017, 215, 338-350. [CrossRef] [PubMed]

44. Kettles, G.J.; Hofinger, B.J.; Hu, P.; Bayon, C.; Rudd, J.J.; Balmer, D.; Courbot, M.; Hammond-Kosack, K.E.; Scalliet, G.; Kanyuka, K. sRNA Profiling Combined With Gene Function Analysis Reveals a Lack of Evidence for Cross-Kingdom RNAi in the Wheat - Zymoseptoria tritici Pathosystem. Front. Plant Sci. 2019, 10, 892. [CrossRef] [PubMed]

45. Raman, V.; Simon, S.A.; Demirci, F.; Nakano, M.; Meyers, B.C.; Donofrio, N.M. Small RNA Functions Are Required for Growth and Development of Magnaporthe oryzae. Mol. Plant Microbe Interact. 2017, 30, 517-530. [CrossRef]

46. Lau, S.K.; Chow, W.N.; Wong, A.Y.; Yeung, J.M.; Bao, J.; Zhang, N.; Lok, S.; Woo, P.C.; Yuen, K.Y. Identification of microRNA-like RNAs in mycelial and yeast phases of the thermal dimorphic fungus Penicillium marneffei. PLoS Negl. Trop. Dis. 2013, 7, e2398. [CrossRef]

47. Dahlmann, T.A.; Kück, U. Dicer-Dependent Biogenesis of Small RNAs and Evidence for MicroRNA-Like RNAs in the Penicillin Producing Fungus Penicillium chrysogenum. PLoS ONE 2015, 10, e0125989. [CrossRef]

48. Dubey, H.; Kiran, K.; Jaswal, R.; Jain, P.; Kayastha, A.M.; Bhardwaj, S.C.; Mondal, T.K.; Sharma, T.R. Discovery and profiling of small RNAs from Puccinia triticina by deep sequencing and identification of their potential targets in wheat. Funct. Integr. Genom. 2019, 19, 391-407. [CrossRef]

49. Kang, K.; Zhong, J.; Jiang, L.; Liu, G.; Gou, C.Y.; Wu, Q.; Wang, Y.; Luo, J.; Gou, D. Identification of microRNA-Like RNAs in the filamentous fungus Trichoderma reesei by solexa sequencing. PLoS ONE 2013, 8, e76288. [CrossRef]

50. Halter, T.; Imkampe, J.; Mazzotta, S.; Wierzba, M.; Postel, S.; Bücherl, C.; Kiefer, C.; Stahl, M.; Chinchilla, D.; Wang, X.; et al. The leucine-rich repeat receptor kinase BIR2 is a negative regulator of BAK1 in plant immunity. Curr. Biol. 2014, 24, 134-143. [CrossRef]

51. Figueiredo, A.; Monteiro, F.; Sebastiana, M. Subtilisin-like proteases in plant-pathogen recognition and immune priming: A perspective. Front. Plant Sci. 2014, 5, 739. [CrossRef]

(C) 2020 by the authors. Licensee MDPI, Basel, Switzerland. This article is an open access article distributed under the terms and conditions of the Creative Commons Attribution (CC BY) license (http://creativecommons.org/licenses/by/4.0/). 